\title{
Investigation of New and Recovered Wood Shipping Platforms in the United States
}

\author{
Nathan Gerber, ${ }^{\mathrm{a}}$ Laszlo Horvath, ${ }^{\mathrm{a}, *}$ Philip Araman, ${ }^{\mathrm{a}}$ and Brad Gething ${ }^{\mathrm{b}}$ \\ This study was performed to acquire key market and raw material usage \\ information for the wood pallet and container industry in 2016. Historical \\ trends in the wood pallet market were also analyzed between 1991 and \\ 2016 using the results of previous Virginia Tech pallet surveys sponsored \\ by NWPCA and U.S. Forest Service. The wooden pallet and container \\ industry produced an estimated 513 million new wood pallets in 2016, \\ which is a $23 \%$ increase since 2011 . Approximately $35 \%$ of this was 48 " $x$ \\ 40 " pallets, which continues to be the dominant standardized pallet size. \\ Approximately $39 \%$ of new wood pallets were custom sizes, which is a \\ significant decrease from the $60 \%$ share found in 2011. Stringer class \\ pallets remained the dominant pallet class with $76 \%$ share, while block \\ pallets and skids only accounted for $21 \%$ and $3 \%$ of the market, \\ respectively. Softwoods accounted for $55 \%$ of the pallet market, while \\ hardwood accounted for $45 \%$. An estimated 326 million pallets were \\ recovered and sold as recycled/ repaired or remanufactured pallets in \\ 2016. The most common size of the recycled or remanufactured pallets \\ was 48 " x 40 ", accounting for $69 \%$ of the recycled market.
}

Keywords: Wood pallet; Survey; Pallet market; Pallet recovery

Contact information: a: Department of Sustainable Biomaterials, Virginia Tech, 1650 Research Center Dr, Blacksburg, VA 24061, USA; b: NWPCA, 1421 Prince Street, Suite 340, Alexandria, VA 22314, USA;

*Corresponding author: lhorvat@vt.edu

\section{INTRODUCTION}

The first official pallet was patented in 1932 by Bill House and George Raymond, Sr. (Raymond 2007). However, the use of pallets only started to grow in the 1940s, as they became valuable tools to meet the demand for increased material handling speed during the Second World War (LeBlanc 2011). Since World War II, the use of pallets has expanded into other industrial applications outside of the military. Today, wooden pallets are used by $93 \%$ of material handling companies (Bond 2018); thus, the wooden pallet industry is important in sustaining the United States economy.

Pallets utilize industrial-grade lumber that would not readily be used otherwise (Bejune 2001). In 1995, it was estimated that the pallet industry consumed $38 \%$ of hardwood lumber produced in the U.S. and $5.6 \%$ of U.S.produced softwood lumber (Bush and Araman 1998). In 2006, pallet production accounted for between $30 \%$ and $33 \%$ of hardwood lumber produced in the U.S. (Bush and Araman 2008).

The majority of wooden pallets are newly constructed from new lumber. In 2011, it was estimated that 416 million new wood pallets were produced, accounting for $56.1 \%$ of pallets produced. (Araman and Bush 2015). This was a 
$5.7 \%$ decrease from the 441 million new wood pallets produced in 2006, which accounted for $57.9 \%$ of the pallets produced that year (Bush and Araman 2008).

A large proportion of pallets are recovered, repaired, or downcycled as other products. In 2011, it was estimated that 474 million pallet cores were recovered (Araman and Bush 2015). Of that amount, approximately 326 million pallet cores were either reused without repair or repaired and then put back into use (Araman and Bush 2015). Pallets that cannot be repaired and broken pallet parts can instead be converted into colored and uncolored landscape mulch, animal bedding, biofuel, furnishing for fiber-based products, or other uses (Bush and Araman 2014).

Due to the volume of new and recovered wood used by the pallet industry, the tracking of historical wood usage and pallet production is important to gauge the current state of the industry. This study provides the wood pallet and container industry with current information on trends in new and used wood pallet production, wood volumes, heat treatment, and byproduct production. Companies in the industry can adopt business strategies to take advantage of current developments in these trends.

\section{Research Objectives}

The main goal of this study was to investigate the use of new and recovered wood in the wooden pallet and container industry for 2016. A paper survey was administered in conjunction with an equivalent online survey to gather data for the entire industry. With the analysis of the responses, this study accomplished its main objective, which was to determine the status of the wooden pallet and container industry, focusing on the following sub-objectives:

1. Determine the types, volumes, and usage trends of new wood used in the U.S. pallet and container industry

2. Determine the volumes, uses, and trends of used or recovered wood by firms in the U.S. pallet and container industry

3. Determine wood material usage trends for the U.S. pallet and container industry on a national and regional level.

\section{EXPERIMENTAL}

\section{Methods}

Survey

A database of companies in the wooden container and pallet manufacturing industry (NAICS Code 321920) was purchased from the NAICS Association (Rockaway, NJ) and was then combined with a list of companies from the National Wooden Pallet and Container Association (NWPCA) to create the list of companies used for this study. Adding the NWPCA database may have biased results towards larger production numbers. The addresses were run through the Virginia Tech mailing service (Blacksburg, VA) to ensure they were valid addresses. Duplicates and invalid addresses were removed, leaving 2,520 companies in the industry to survey. To ensure survey reliability, the first question of the survey asked for those that were not in the industry to not answer questions but to return the survey with a pre-paid postage envelop. Each company was contacted and asked to provide information on raw material usage in their pallet 
and container production operations, production numbers for different sizes and classes of pallets, and non-confidential business information among other questions. The business information asked about included data on the distribution of sales between goods and services, employee numbers, days in operation, and average number of shifts for the calendar year 2016. Some questions were asked in a way to allow for differentiation within four geographical regions. The regions used were the U.S. geographical regions as defined by the U.S. Census Bureau: Northeast, Midwest, South, West (U.S. Census Bureau 2018).

Data were collected using a mailed questionnaire based on previous Virginia Polytechnic Institute and State University surveys (Cristoforo et al. 1993; Reddy et al. 1995; Bejune et al. 2002; Bush and Araman 2008; Bush and Araman 2014). Many questions in the questionnaire were changed from the previous surveys in order to refine the type of data collected, but the questions were kept similar enough to allow for historical comparisons. All questions were reviewed for validity by the Science and Technology Committee of the National Wooden Pallet and Container Association (Alexandria, VA) as well as Virginia Tech's Laboratory for Interdisciplinary Statistical Analysis (Blacksburg, VA). The questionnaire was created as a paper version and an identical online version using Qualtrics (Provo, Utah). The online version was made accessible using a unique ID that was provided to the companies with the paper survey when it was sent out. Duplicate responses were identified using the unique ID and were treated as one response.

Three mailings were performed between late May and June of 2017, but not exceeded to comply with harassment policy (Institutional Review Board 2010). The first mailing was the paper questionnaire, the second mailing was a reminder postcard, and the third mailing was another copy of the paper questionnaire. The third mailing was sent only to companies that had not yet responded. Each mailing was sent out two weeks after the previous mailing.

\section{Data}

After finishing the collection of the questionnaires, the data were checked for validity. Outliers were investigated to obtain rational reasons for their existence. Data were screened for duplicates, which were then removed. Data checking is covered further in the Data Cleaning subsection. Data from late responses was compared to data from early responses in order to determine if there were any systematic differences between late and early responders, which is further discussed in the Late Response Bias subsection.

The received responses were analyzed based on the question type. The results of percentage-based questions were also multiplied with relevant reported statistics from other questions such as number of pallets, bdft lumber used, etc. on a by-company-basis in order to give weight to the responses. These new statistics were added together to get the industry parameters. This gives more weight to companies that produce more of pallets or use more lumber and therefore gives a better representation of the industry.

For estimations of industry totals, such as total pallets produced, the data collected on a regional level were then added together to show the national total. Totals were calculated by scaling up the answers given in the survey responses. This scaling was performed by using the total number of employees reported from 
the surveys as a percentage of the total number of employees in the industry as reported by the US Census Bureau's employment numbers of NAICS 321920 in 2016 (Bejune 2001). This percentage was then used to calculate values representative to the overall industry. For example, if companies representing $20 \%$ of total employees responded that they produced 100 pallets, then industry would be responsible for producing a total of 500 pallets (100 pallet / 0.2). This peremployee basis assumes that all work is being done at the same level of automation, so this method may lead to inflated production numbers.

Some of the data were analyzed on a regional basis to provide comparisons between the regions. Regional comparisons were conducted using nonparametric tests, since the data were not normally distributed. Spearman's Correlation and Kruskal-Wallis Test were utilized to determine whether any one region was significantly different from the other regions with respect to the analyzed question at the $\alpha=0.05$ level (Laerd Statistics 2018). When questions asked for percentages instead of units, regional comparisons were conducted with chi-squared tests at the $\alpha=0.05$ level.

The results were compared to historical data collected for 1992, 1993, 1995, 1999, 2006, and 2011 (Christoforo 1993; Redy et al. 1995; Bejune 2001; Bush and Araman 2008; Bush and Araman 2014). In addition, during the analysis the numbers were rounded to the nearest whole percent; thus not all results add up to exactly $100 \%$.

\section{Late response bias}

It is important to determine whether the firms that responded were systematically different from those that did not. This potential bias, called nonresponse bias, was simulated by late response bias by considering late respondents as a proxy for non-respondents (Armstrong and Overton 1977). Respondent companies were separated into 2 groups: early respondents and late respondents. Early respondents were those that responded before June $21^{\text {st }}$, 2017, which is around the time that the companies would be receiving the second mailing of the questionnaire, so these respondents would be responding to the first mailing. Late respondents were those that responded on June $21^{\text {st }}, 2017$, or later, so they were responding to the second mailing of the questionnaire. Companies were further broken down into 3 categories: small (20 or fewer employees), medium (21 to 75 employees), and large (76 or more employees). Early and Late respondents were compared based on being small, medium, or large companies. They were further compared based on their responses to the questions regarding the production of new, recycled/recovered, and remanufactured pallets, as well as the collection of pallet cores. No significant difference was found using Wilcoxon tests.

\section{Data cleaning}

In order to ensure the quality of the data received, responses were screened for accuracy. Firms with responses that did not make sense in the context of the questions asked were contacted and asked for clarification. If the firm did not respond, their responses were evaluated based on type of question. Responses to percentage-based questions that did not add up to $100 \%$ were removed to avoid unfairly biasing one category over another. Outliers were evaluated based on company size and employee count, and they were removed if they were 
unrealistically high or low. Reported lumber volume per pallet produced was evaluated. Realistic values were expected to be between 0.5 board feet and 30 board feet per pallet. If a response was above this range by a factor of 1,000 , it was assumed that the respondent likely reported by the board feet instead of by the requested thousand board feet, and their response was adjusted accordingly. If the response was outside of the normal range, and the company did not respond to contact, then their response for reported board feet was removed.

\section{RESULTS AND DISCUSSION}

\section{Respondents}

Out of the original pool of 2,520 companies, 106 were no longer in the industry. Of the remaining 2,414 valid companies within the wooden pallet and container industry, 179 responded, resulting in an adjusted response rate of $7.4 \%$.

The response rate varied per question due to question relevance to each respondent (Fig. 1). Question 1 was answered by all valid respondents since it was a yes-or-no question about whether or not the respondent was in the pallet and container industry. Questions after Question 13 only pertained to companies who repair pallets; thus not all respondent completed these questions.

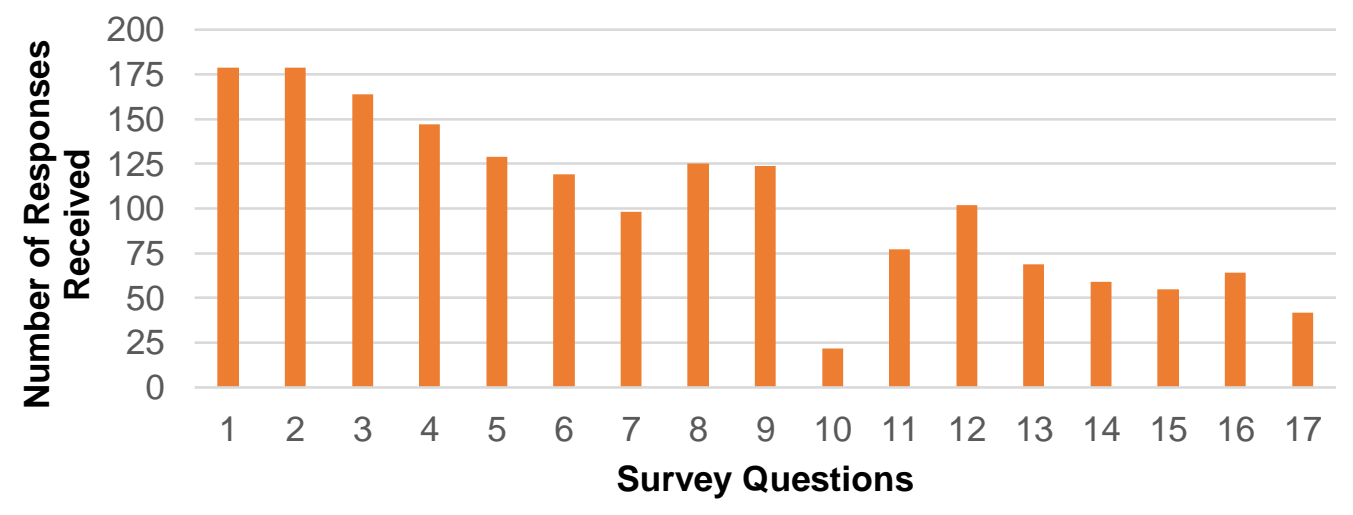

Fig. 1. Response rate for each question

These responses accounted for 248 facilities in the United States. Respondents reported their primary source of income in 2016 as one of five options: new wood pallet manufacturing (51.9\%), recycled/repaired/remanufactured wood pallet production $(24.0 \%)$, brokering or wholesaling pallets $(11.7 \%)$, wood crate manufacturing (6.7\%), and other uses (5.7\%), as can be seen in Table 1. From 2011 to 2016, the percentage of companies that reported selling new wood pallets as their primary source of income decreased approximately the same amount as the percentage of companies that reported that brokering or wholesaling pallets as their primary source of income increased. This implies a trend towards brokering or wholesaling pallets, possibly as a form of third-party management. While reported company performances varied, overall respondents indicated that their sales volume has increased an average $10 \%$. 
Table 1. Products Accounting for the Estimated Largest Sales Dollars for Companies in the Wooden Pallet and Container Industry (Historical Perspective)

\begin{tabular}{|l|l|l|l|l|l|}
\hline Year & $\begin{array}{l}\text { New } \\
\text { Pallets }\end{array}$ & $\begin{array}{l}\text { Recycling, } \\
\text { Repair, } \\
\text { Remanufacturing } \\
\text { Wood Pallets }\end{array}$ & $\begin{array}{l}\text { Brokering or } \\
\text { Wholesaling } \\
\text { Pallets }\end{array}$ & $\begin{array}{l}\text { Crate } \\
\text { Manufacturing }\end{array}$ & Other \\
\hline 2011 & $58.9 \%$ & $25.1 \%$ & $1.3 \%$ & --- & $14.7 \%$ \\
\hline 2016 & $51.9 \%$ & $24.0 \%$ & $11.7 \%$ & $6.7 \%$ & $5.7 \%$ \\
\hline
\end{tabular}

Most respondents indicated that they only had one production facility (76\%). Most multi-facility responders indicated that they had 2 facilities (14\%). The rest of the responses indicated 3 facilities (4\%), 4 facilities (2\%), 5 facilities $(3 \%), 7$ facilities $(<1 \%)$, and 10 facilities $(<1 \%)$.

The survey respondents employed a total of about 9,906 employees, which accounts for 19\% of the total 51,345 employees in the industry (US Census Bureau, 2018). The South had the most reported employees at 4,614. The Midwest had the second highest number of reported employees at 2,604. The Northeast had the second lowest reported number of employees at 1,484, and the West had the lowest reported number of employees at 1,204.

Approximately 513 million new wood pallets were produced in 2016, as is shown in Figure 2. This is a 23\% increase from the pallets produced in 2011. Approximately 326 million recycled or remanufactured wood pallets were produced in 2016. This is the same amount produced in 2011. In addition, 6\% of the total pallets were remanufactured pallets ( 52.9 million). These estimates were obtained using the calculations shown in the Appendix.

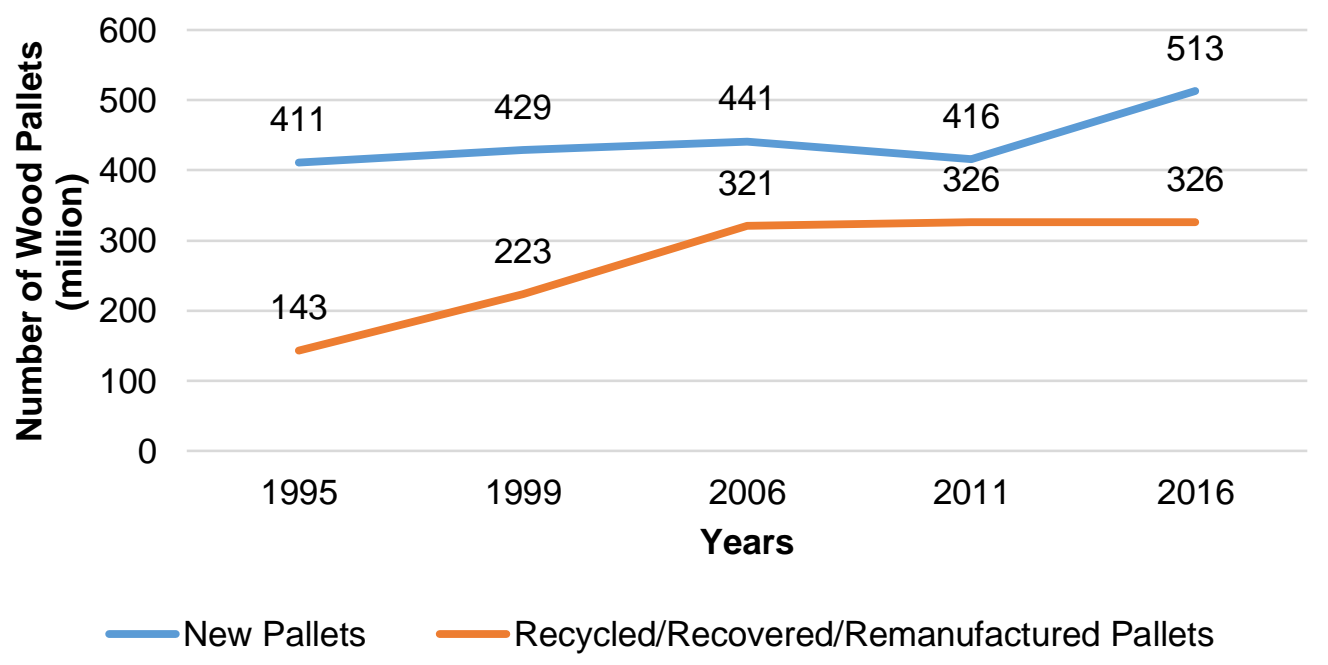

Fig. 2. Estimated wooden pallet production in the U.S.: 1995 - 2016

Simple linear regressions were run to compare historical pallet production with Gross Domestic Product (GDP). Six bivariate analyses were run, comparing new, used, and total pallet production to U.S. manufacturing GDP as reported by the U.S. Bureau of Economic Analysis (Bureau of Economic Analysis 2018) and 
U.S. nominal GDP as reported by the World Bank (World Bank 2018). Strong linear correlations ( $R$ squared values above 0.80 ) were found between used pallet production and both forms of GDP, as well as total pallet production and both forms of GDP. This strong correlation shows that there might be a connection between pallet production and economic performance. It is likely because manufacturing production growth means that more products must be transported and are put on pallets to do so.

The South produced the largest number of new pallets with $39 \%$ of total new pallets being manufactured here. The South also repaired the largest number of pallets with $36 \%$ of total recycled and $43 \%$ of the total remanufactured pallets. The West produced the fewest new pallets. Only $14 \%$ of total new pallets manufactured came from the West. The Northeast produced the fewest repaired pallets with only $12 \%$ of total recycled and $14 \%$ of the remanufactured pallets as seen in Table 2.

Table 2. Estimate Regional Distribution of New, Recycled, and Remanufactured Wooden Pallet Production in the U.S. in 2016

\begin{tabular}{|c|c|c|c|c|c|}
\hline Pallet Type & Northeast & Midwest & South & West & Total \\
\hline New & $22 \%$ & $25 \%$ & $39 \%$ & $14 \%$ & $100 \%$ \\
\hline Recycled & $12 \%$ & $26 \%$ & $36 \%$ & $26 \%$ & $100 \%$ \\
\hline Remanufactured & $14 \%$ & $29 \%$ & $43 \%$ & $14 \%$ & $100 \%$ \\
\hline Total Pallets & $18 \%$ & $26 \%$ & $38 \%$ & $18 \%$ & $100 \%$ \\
\hline
\end{tabular}

Spearman's Correlation, which assumes the data are not normal, found no statistically significant differences in mean regional pallet production per facility for new, recycled, or remanufactured pallets. This means that the differences in pallet production between regions are likely due to a difference in the number of facilities in that region rather than differences in productivity or facility size.

Of the total produced, $38 \%$ of new wood pallets were heat-treated according to phytosanitary regulations, which is higher than the $21 \%$ reported in 2006. Twenty-eight percent of recycled pallets were heat-treated. Heat-treatment is regulated by International Standards for Phytosanitary Sanitation 15 (ISPM 15), which was adopted in the U.S. in late 2005 (Haack et al. 2014). The recent increase in the number of heat-treated pallets might be attributed to the time that it takes to fully implement policies in a global scale. The South produced the highest percentage of heat-treated new wood pallets at $51 \%$. The Midwest produced the highest reported percentage of heat-treated recycled or remanufactured wood pallets at $24 \%$.

\section{New Wood Material Use}

Responses indicated that 9.16 billion board feet of new lumber were consumed to produce both new and repaired wood pallets. This accounts for $21.8 \%$ of the 42 billion board feet of total new lumber produced in the U.S. in 2016 (Madison's Lumber Reporter 2017). Approximately 8.56 billion board feet of new lumber, or $20.4 \%$ of wood produced in the U.S. (Madison's Lumber Reporter 2017), was consumed for the production of new wood pallets.

It was estimated that 0.60 billion board feet of new lumber, or $1.4 \%$ of U.S. lumber production (Madison's Lumber Reporter 2017), went into the repair and 
remanufacturing of wood pallets. Pallet repair used an estimated 0.44 billion board feet of new lumber. Pallet remanufacturing used an estimated 0.16 billion board feet of new lumber.

The West consumed the largest amount of softwood, with $32 \%$ of total lumber in the U.S. being consumed for pallet production. This was mostly comprised of spruce, pine, and fir, which made up $82 \%$ of the total lumber consumed for pallet production in the West. The South consumed the second largest amount of softwood, with $33 \%$ of total lumber consumed for pallet production. This was mostly southern pine, which comprised $57.5 \%$ of total lumber consumed by the South. This is in line with wood species maps of the U.S. that show high growth rates of spruce, pine, and fir in the West and high growth rates of southern pine in the South (Joyce et al. 2001). The largest consumer of hardwood was the South, which used $17 \%$ of total lumber consumed for pallet production. This was mostly in the form of high-density hardwoods, which made up 59\% of total hardwood lumber consumed in the South for pallet production, as seen in Table 3. This is in accordance with forestry maps of the U.S., which show that most high-density hardwoods are grown in the Midwest and South (Joyce et al. 2001).

The results also show that although the West only produced $18 \%$ of the pallets, it consumed $33 \%$ of the lumber used for pallet production. By contrast, the Midwest consumed $14 \%$ of the material and produced $26 \%$ of the pallets. These results could indicate that the West produced more larger custom pallets, while the Midwest produced smaller pallets. However, the result warrants more investigation on the topic.

It is generally assumed that pallet and container companies use locally sourced wood, and these results back up this assumption. Roughly $6 \%$ of new wood that was used to manufacture or repair wood pallets was imported from outside of the United States. Of the imported wood, most of it was sourced from Canada (99\%), and the rest came from South America $(<1 \%)$ or other countries $(<1 \%)$. No wood was sourced from Mexico or Central America.

The type of wood consumed in the four regions differed, as shown in Fig. 3. The wood imported outside of the U.S. is excluded from this analysis. The wood consumed for pallet production in the West was $97.9 \%$ softwood and $2.1 \%$ hardwood. Meanwhile, an opposite trend was observed in the Northeast, where $91.4 \%$ of the wood consumed was hardwood while $8.6 \%$ was softwood. In the South, wood consumed was $58.7 \%$ softwood and $41.3 \%$ hardwood, and in the Midwest, $60.0 \%$ of wood consumed was hardwood and $40.0 \%$ was softwood. Using the chi squared test, it was found that regional proportional consumption of hardwood and softwood consumption were significantly different.

Using Spearman's Correlation, there was no significant difference in mean softwood consumption between companies of different regions. Therefore, any differences seen in softwood consumption among the different regions could be due to a difference in the number of companies per region. However, the West had 9 responses, and so it may have had too small of a sample size for this analysis. 
Table 3. Estimated Wood Species Consumption as a Percentage of Total Wood Consumption for Wooden Pallet Production in 2016 by Region

\begin{tabular}{|c|c|c|c|c|c|}
\hline & Species Groups & Northeast & Midwest & South & West \\
\hline \multirow[t]{3}{*}{ Hardwood } & Low Density Hardwood & $2 \%$ & $1 \%$ & $4 \%$ & $<1 \%$ \\
\hline & Medium Density Hardwood & $2 \%$ & $1 \%$ & $3 \%$ & $0 \%$ \\
\hline & High Density Hardwoods & $7 \%$ & $4 \%$ & $10 \%$ & $0 \%$ \\
\hline \multirow[t]{4}{*}{ Softwood } & SPF & $<1 \%$ & $4 \%$ & $<1 \%$ & $27 \%$ \\
\hline & Southern Pine & $<1 \%$ & $<1 \%$ & $23 \%$ & $0 \%$ \\
\hline & Douglas-Fir & $<1 \%$ & $<1 \%$ & $<1 \%$ & $5 \%$ \\
\hline & $\begin{array}{c}\text { Other North American } \\
\text { Softwoods }\end{array}$ & $<1 \%$ & $<1 \%$ & $<1 \%$ & $<1 \%$ \\
\hline \multirow{5}{*}{$\begin{array}{l}\text { Imported } \\
\text { Wood }\end{array}$} & Canada Import & $2 \%$ & $3 \%$ & $0 \%$ & $1 \%$ \\
\hline & Mexico Import & $0 \%$ & $0 \%$ & $0 \%$ & $0 \%$ \\
\hline & South American Import & $0 \%$ & $0 \%$ & $<1 \%$ & $0 \%$ \\
\hline & Central American Import & $0 \%$ & $0 \%$ & $0 \%$ & $0 \%$ \\
\hline & Other Imports & $0 \%$ & $<1 \%$ & $<1 \%$ & $0 \%$ \\
\hline \multicolumn{2}{|c|}{ Total Wood Consumption } & $13 \%$ & $14 \%$ & $40 \%$ & $33 \%$ \\
\hline
\end{tabular}

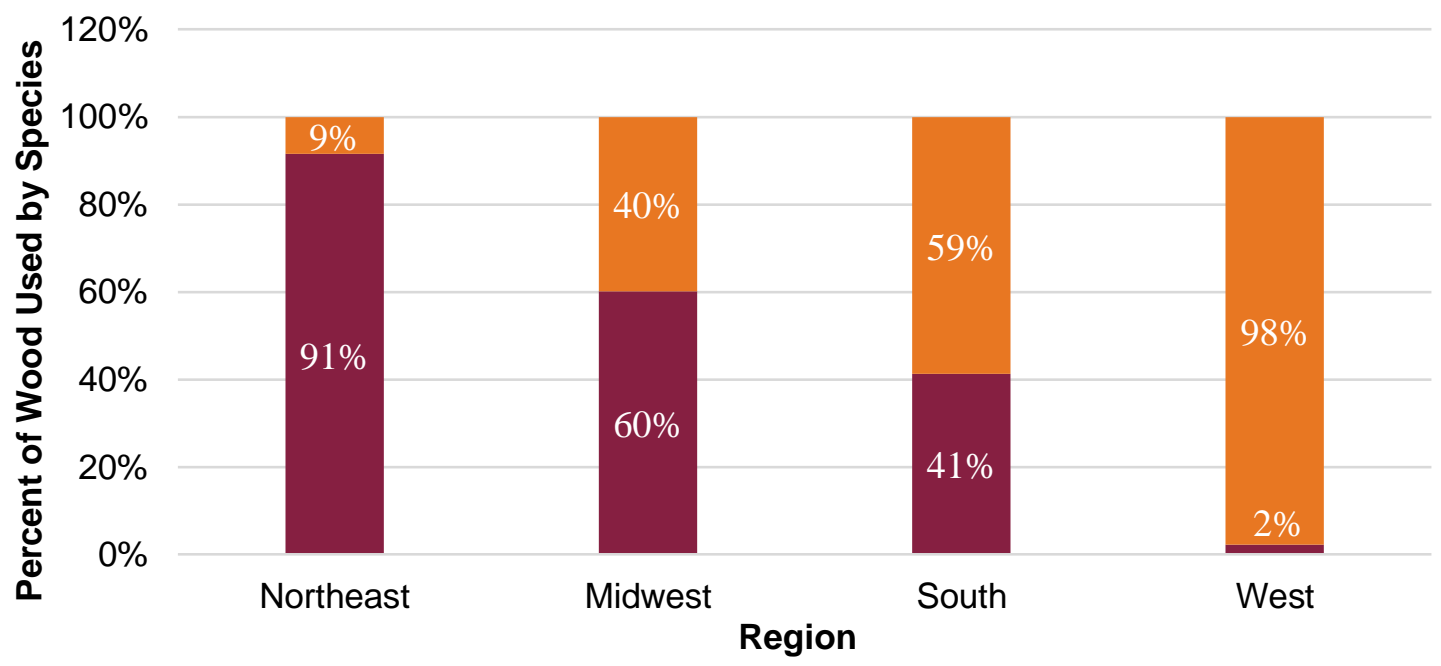

- Hardwood $\square$ Softwood

Fig. 3. A regional analysis of U.S. softwood and hardwood used for pallet production. White text represents the percent of hardwood used per region.

\section{Hardwood}

Responses indicated that 4.13 billion board feet of hardwood, which is $45 \%$ of wood used to produce pallets, was consumed in the production or repair/remanufacturing of wood pallets. Of this, 4.07 billion board feet of hardwood were used to produce new pallets in 2016, as indicated in Table 4. This puts hardwood use near pre-2011 levels, as shown in Table 4. 
Table 4. Estimated Volume of New Wood Used for the Production of New, Recycled, and Remanufactured Pallets

\begin{tabular}{|c|c|c|c|}
\hline Year & $\begin{array}{c}\text { Billion Board Feet of } \\
\text { Hardwood }\end{array}$ & $\begin{array}{c}\text { Billion Board Feet of } \\
\text { Softwood }\end{array}$ & $\begin{array}{c}\text { Total Board Feet } \\
\text { (Billion) }\end{array}$ \\
\hline 1999 & 4.5 & 2.1 & 6.6 \\
\hline 2006 & 4.6 & 2.6 & 7.2 \\
\hline 2011 & 2.6 & 4.3 & 6.9 \\
\hline 2016 & 4.13 & 5.03 & 9.16 \\
\hline
\end{tabular}

The hardwood consumption for all pallets accounts for $43 \%$ of the 9.5 billion board feet of hardwood lumber produced in the U.S. in 2016 (Madison's Lumber Reporter 2017). This is approximately 8\% higher than the amount of hardwood used in producing pallets in 1999 (35.4\%) and 2015 (34.9\%) (Bumgardner 2016). However, the Madison Lumber Reporter survey doesn't cover pulpwood that is used to make parts, as companies don't often keep track of this; so the percentage of hardwood might be lower than reported. It should be reasoned that this $43 \%$ is the upper limit of the percentage of pallet wood in the lumber industry. The increase in hardwood use since 2011 is likely due to the recovery of the market from the Great Recession, which caused a decline in lumber production in the U.S. Out of the total 4.13 billion board feet used in pallet production, 2.25 billion board feet was used for hardwood lumber and cants (54.5\%), while 1.88 billion board feet was used for hardwood parts $(45.5 \%)$. The utilization of hardwood parts increased significantly from the previous years where only $16 \%$ (1999), 8.9\% (2006) and 20\% (2011) of the lumber used for pallet manufacturing came in the form of parts. For new wood pallet production, an estimated 4.08 billion board feet was used, while 0.04 billion board feet was used for recycled pallet production and 0.01 billion board feet was used for remanufactured pallet production. Most of the hardwood used was high-density hardwood (62\%). Low density (19.4\%) and medium density (17.6\%) hardwoods make up the remaining $38 \%$ of hardwood used.

\section{Softwood}

Responses indicated that 5.03 billion board feet of softwood, which is $55 \%$ of total wood used to produce or repair/remanufacture wood pallets. Of this, 4.48 billion board feet of softwood were used to produce new pallets in 2016. This was a lower proportion than the softwoods consumed in 2011 (Table 5). An estimated 0.40 billion board feet was used to produce recycled pallets. An estimated 0.15 billion board feet were used to produce remanufactured wood pallets. The softwood consumed to produce all pallets accounted for approximately $15 \%$ of U.S. softwood lumber production in 2016 (Madison's Lumber Reporter 2017). Approximately 2.79 billion board feet were consumed to form softwood lumber or cants, and 2.24 billion board feet were consumed to form other softwood parts $(44.5 \%)$. The utilization of softwood parts increased significantly from the previous years where only 29\% (1999), 22\% (2006) and 30\% (2011) of the lumber used for pallet manufacturing came in the form of parts. The most-used softwood species were spruce, pine, and fir (51\%), followed by southern pine (39\%), Douglas-fir (8\%) and other North American softwoods (2\%), as shown in Table 5. Historically, softwood pallets were primarily made of southern pine, which has now traded places in 
market dominance with spruce, pine, and fir. The decrease in other wood, when compared to 2011, is likely due to the inclusion of Douglas-fir with other species in the 2011 survey, whereas it was asked about separately in the 2016 survey.

Table 5. Estimated Percent Use of Softwood Species for Wood Pallets: 1991 to 2016

\begin{tabular}{|c|c|c|c|c|}
\hline Year & SPF & Southern Pine & Douglas-Fir & Other \\
\hline 1991 & --- & $40 \%$ & $29 \%$ & $32 \%$ \\
\hline 1993 & --- & $34 \%$ & $24 \%$ & $42 \%$ \\
\hline 1995 & $31 \%$ & $41 \%$ & $11 \%$ & $17 \%$ \\
\hline 1999 & $25 \%$ & $48 \%$ & $10 \%$ & $16 \%$ \\
\hline 2006 & $36 \%$ & $54 \%$ & $4 \%$ & $7 \%$ \\
\hline 2011 & $32 \%$ & $41 \%$ & --- & $26 \%$ \\
\hline 2016 & $51 \%$ & $39 \%$ & $8 \%$ & $2 \%$ \\
\hline
\end{tabular}

\section{New Pallet Production}

Of the estimated 513 million new pallets produced, 68\% were produced using non-certified wood, 16\% using SFI certified wood, $8 \%$ using FSC certified wood, and $9 \%$ using wood with other certifications. This level of certification $(32 \%)$ is much higher than the level of certification in 2011 (3.8\%). The question involving environmental certifications received a very low response rate (only 22 usable responses), so these percentage estimates of certification are unreliable in this instance. Environmentally certified wood had yet to penetrate pallet markets in 2011, but sources have grown substantially since then. From 2011 to 2015, SFI certified forests increased from approximately 200 million acres in North America to approximately 300 million acres (Sustainable Forest Initiative 2019). While definite conclusions cannot be drawn in this study, the results indicate that further investigation is warranted in the future.

It was reported that $76 \%$ of new wood pallets were stringer pallets, $21 \%$ were block pallets, and 3\% were skids or other types of pallets. The proportion of block pallets more than doubled since 2011 (Fig. 4). In the meantime, the proportion of stringer pallets has declined greatly since 2011 and is at the lowest proportion seen since 1999 . The most common standardized size of new pallets is 48 " x 40 " (35\%), followed by 48" x 48" (7\%). The other sizes asked about in the survey were 40" x 48" (4\%), 48" x 45" (5\%), 48" x 42" (3\%), 48” x 36" (1\%), 42" x 42" (5\%), 37" x 37" (<1\%), and $800 \mathrm{~mm}$ x $1200 \mathrm{~mm}(1 \%)$. These sizes were asked for because they are used for, respectively, the grocery industry, drums, military, the automotive industry, the chemical industry, the beverage and packaged paper industries, paints, the beverage industry, and international trade (Tranpak 2018). The remaining 39\% of pallets were reported as other sizes. The historical comparison for pallet sizes can be seen in Table 6 . The proportion of new pallets being 48 " $\mathrm{x} 40$ " pallets is at the highest seen in the last 10 years. There are several possible explanation for this observed transition: industry consolidation is eliminating smaller pallet companies that focused on producing custom sizes, increase in survey clarity that provided better delineation between pallet sizes, a natural industry trend toward standardization, or the natural variation of surveys. 


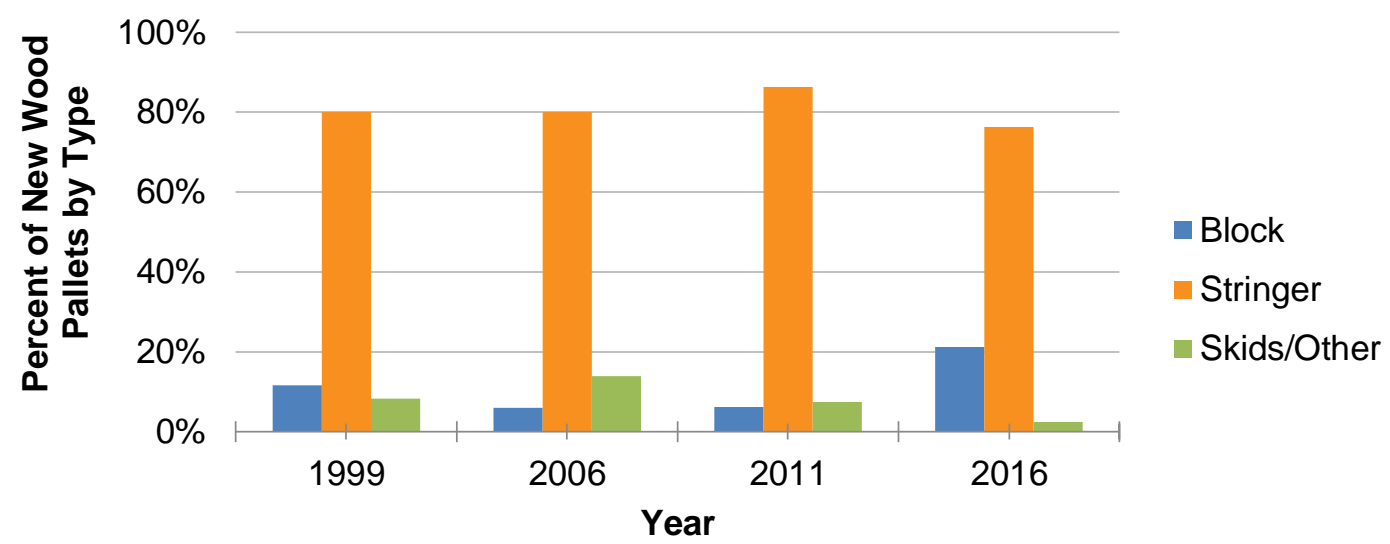

Fig. 4. New wood pallet classes as a percentage of new wood pallet production: $1999-2016$

Table 6. Estimated Percentages of New Wood Pallet Sizes Produced in the U.S.: 2006 - 2016

\begin{tabular}{|c|c|c|c|c|c|c|c|c|c|c|}
\hline Year & $\begin{array}{c}48 " \\
x \\
40 "\end{array}$ & $\begin{array}{c}40 " \\
x \\
48 "\end{array}$ & $\begin{array}{c}48 " \\
x \\
48 "\end{array}$ & $\begin{array}{c}48 " \\
x \\
45^{\prime \prime}\end{array}$ & $\begin{array}{c}48 " \\
\text { X } \\
42 "\end{array}$ & $\begin{array}{c}48 " \\
x \\
36 "\end{array}$ & $\begin{array}{c}42 " \\
x \\
42 "\end{array}$ & $\begin{array}{c}37 " \\
x \\
37 "\end{array}$ & $\begin{array}{c}800 \\
X \\
1200 \\
\mathrm{~mm}\end{array}$ & $\begin{array}{c}\text { Othe } \\
\mathbf{r}\end{array}$ \\
\hline 2006 & $27 \%$ & $5 \%$ & $4 \%$ & $2 \%$ & $4 \%$ & $2 \%$ & $5 \%$ & $2 \%$ & --- & $50 \%$ \\
\hline 2011 & $24 \%$ & $3 \%$ & $4 \%$ & --- & --- & $2 \%$ & $5 \%$ & $2 \%$ & $1 \%$ & $60 \%$ \\
\hline 2016 & $35 \%$ & $4 \%$ & $1 \%$ & $5 \%$ & $3 \%$ & $1 \%$ & $5 \%$ & $<1 \%$ & $1 \%$ & $39 \%$ \\
\hline
\end{tabular}

Wood waste from new pallet manufacturing was used for colored landscape mulch $(9.5 \%)$, other landscape mulch (24.7\%), animal bedding (17.3\%), pellets and other compressed wood fuel (1.8\%), non-compressed wood fuel (44.8\%), and other uses $(1.9 \%)$. No wood waste from new wood pallet manufacturing was sent to the landfill.

\section{Pallet Repair, Recycling, and Remanufacturing Pallet recovery}

It was estimated that 390 million pallets were recovered for further use in 2016. Of these recovered pallets, $91 \%$ were stringer pallets and $9 \%$ were block pallets. It was estimated that, of all pallets recovered, $65 \%$ were 48 " x 40 " stringer pallets; meanwhile, $7 \%$ were 48 " x 40 " block pallets. This proportion of 48 " $\mathrm{x} 40$ " block pallets is higher than the $3 \%$ recovered in 2011.

Respondents indicated that the sizes of pallets they recovered were 48 " $\mathrm{x}$ 40 " (69\% of recovered pallets), 40 " x 48 " (3\% of recovered pallets), 48 " x 48 " (3\% of recovered pallets), 48" x 45 " ( $3 \%$ of recovered pallets), 48 " x 42 " ( $2 \%$ of recovered pallets), 48 " x 36 " ( $2 \%$ of recovered pallets), 42 " x 42 " (3\% of recovered pallets), 37" x 37" (4\% of recovered pallets), $800 \mathrm{~mm} \times 1200 \mathrm{~mm}(<1 \%$ of recovered pallets), and other sizes (11\% of recovered pallets). This is similar to the sizes of recovered pallets in 2012, when 48 " x 40 " pallets were $81 \%$ of recovered pallets (Park et al. 2016). 


\section{Utilization of recovered pallets}

It was estimated that 326 million recovered pallets were repaired and sold as used pallets (Appendix), accounting for $64.7 \%$ of recovered pallet cores. This is roughly the same proportion as in previous years. Approximately 84 million of the recovered pallets were dismantled and used for other purposes. The second-highest use of recovered pallets was to dismantle them for other uses $(18.1 \%)$. The remaining uses for recovered pallets includes those sold without repair $(5.5 \%)$, those that are ground or chipped $(10.6 \%)$, those sent to the landfill $(0.3 \%)$, as well as other uses $(0.9 \%)$. The historical perspective can be seen in Table 7 . Selling pallets without repair has decreased from $11 \%$ to $5.5 \%$ since 2011, and this is at its lowest proportion of utilization seen since 1992. Pallet dismantling has increased $2 \%$ since 2011, and this is the highest proportion seen since 1995. Grinding and chipping operations have remained the same since 2011. Pallet repair for 48" x 40" stringer pallets is estimated to generate $0.19 \mathrm{~kg}$ of $\mathrm{CO}_{2}$ equivalents per pallet (Park et al. 2016). Using this as a baseline, there were more than 100 million $\mathrm{kg}$ of $\mathrm{CO}_{2}$ equivalents produced during pallet repair and remanufacturing.

Table 7. Estimated Percentage of Processes of Used Pallets Received at U.S. Landfills: 1991 - 2016

\begin{tabular}{|c|c|c|c|c|c|c|}
\hline Year & $\begin{array}{c}\text { Reused } \\
\text { Without } \\
\text { Repair }\end{array}$ & Repaired & Disassembled & $\begin{array}{c}\text { Ground } \\
\text { or } \\
\text { Chipped }\end{array}$ & Landfilled & Other \\
\hline 1991 & $15 \%$ & $62 \%$ & $14 \%$ & $8 \%$ & --- & $1 \%$ \\
\hline 1993 & $13 \%$ & $61 \%$ & $15 \%$ & $8 \%$ & --- & $2 \%$ \\
\hline 1995 & $10 \%$ & $63 \%$ & $18 \%$ & $8 \%$ & $1 \%$ & $1 \%$ \\
\hline 1999 & $8 \%$ & $70 \%$ & $16 \%$ & $5 \%$ & $1 \%$ & $<1 \%$ \\
\hline 2006 & $10 \%$ & $67 \%$ & $16 \%$ & $6 \%$ & $<1 \%$ & $1 \%$ \\
\hline 2011 & $11 \%$ & $69 \%$ & $16 \%$ & $3 \%$ & $<1 \%$ & $<1 \%$ \\
\hline 2016 & $5 \%$ & $65 \%$ & $18 \%$ & $11 \%$ & $<1 \%$ & $1 \%$ \\
\hline
\end{tabular}

In 2016, approximately than 25 million pallets were sent to landfills (Shiner et al. 2018). This means that only $3 \%$ of all new pallets produced in the US are being sent to landfills. Out of the 25 million, relatively few pallets are sent to the landfill from pallet repair facilities ( 1.4 million). This is mostly because of the expenses associated with landfilling (Shiner et al. 2018) and because taking actions that add value to the product further enhances relationships along the supply chain (Sanchez et al. 2011).

\section{Utilization of ground or chipped pallets}

It was estimated that 4.3 million tons of used pallets were ground or chipped. Most of this wood waste was sold as colored landscape mulch (921 thousand tons) or converted into non-compressed wood fuel (1.44 million tons). The rest of the ground or chipped wood waste was used for other landscape mulch (335 thousand tons), animal bedding (208 thousand tons), or for other uses (1.40 million tons). Animal bedding is a popular end of life utilization for broken wood pallets; contamination that would inhibit their use around animals is not prevalent (White and McLeod 1989). None of the ground or chipped wood waste was used for compressed wood fuel, such as pellets, nor was it landfilled, which would have 
been consistent with past historical trends, as shown in Table 8.

Table 8. Estimated Percent Use of Ground or Chipped Pallets: 1991 2016

\begin{tabular}{|c|c|c|c|c|}
\hline Year & Landscape Mulch & Animal Bedding & Fuel & Other Uses \\
\hline 1991 & $12.3 \%$ & $5.8 \%$ & $53.1 \%$ & $28.8 \%$ \\
\hline 1993 & $18.5 \%$ & $17.1 \%$ & $41.6 \%$ & $22.9 \%$ \\
\hline 1995 & $18.7 \%$ & $7.4 \%$ & $43.2 \%$ & $30.7 \%$ \\
\hline 1999 & $54.3 \%$ & $7.7 \%$ & $22.8 \%$ & $15.2 \%$ \\
\hline 2006 & $62.1 \%$ & $4.4 \%$ & $29.2 \%$ & $4.3 \%$ \\
\hline 2011 & $54.3 \%$ & $10.0 \%$ & $30.0 \%$ & $5.7 \%$ \\
\hline 2016 & $37.5 \%$ & $4.2 \%$ & $30.0 \%$ & $28.3 \%$ \\
\hline
\end{tabular}

\section{CONCLUSIONS}

1. The wooden pallet production in the United States has increased to 839 million pallets, which is a $13 \%$ increase compared to 2011 . New pallet production has increased approximately $23 \%$ to 513 million pallets, and used pallet production has stayed constant since 2011 at approximately 326 million pallets.

2. New wood pallets were reported as predominantly stringer pallets (76\%). Block pallets and skids only accounted for $21 \%$ and $3 \%$ of the industry, respectively. This is an increase in block pallet production and the lowest proportion of stringer pallet production since 1999 .

3. The most common size for new wood pallets remains the 48 " $\mathrm{x} 40$ " pallet, which accounts for $35 \%$ of all new wood pallets produced. This is an $8 \%$ increase from 2006. Meanwhile, non-standard pallet sizes accounted for 39\% of new wood pallets produced. This is a $11 \%$ decrease from 2006.

4. The results show that the U.S. pallet industry consumed 9.16 billion board feet of new wood for the production of new and used wood pallets, which account for $21.8 \%$ of lumber produced in the United States (Madison Lumber Reporter 2017). Hardwood accounts for 4.13 billion board feet, or $45 \%$, of reported U.S. hardwood production (Madison Lumber Reporter 2017). Softwood accounts for 5.03 billion board feet, or 15\%, of U.S. softwood production (Madison Lumber Reporter 2017).

5. Roughly 326 million recovered pallets were repaired or remanufactured and then sold as used pallets, accounting for $64.6 \%$ of recovered pallet cores. The use of recycled and remanufactured pallets remained at nearly the same $42 \%$ proportion of the industry that it has been since 2006 .

6. Wood waste use from recovered pallets has changed since 2011. The proportional use of landscape mulch has declined, which coincides with the percentage increase in other uses. Animal bedding production fell in proportion since 2011, and it now has returned to 2006 levels. 


\section{ACKNOWLEDGEMENTS}

The research project was financially supported by the Pallet Foundation of the National Wooden Pallet and Container Association and the Southern Research Station of the U.S. Forest Service.

\section{REFERENCES CITED}

Araman, P. A., and Bush, R. J. (2015). "New and used pallet information plus other topics," in: WPS 2015 Annual Meeting, Rancho Mirage, CA, USA, (http://www.bobtheriault.com/assets/2015araman_00.pdf ), Accessed 19 Nov 2018.

Armstrong, J. S., and Overton, T. S. (1977). "Estimating nonresponse bias in mail surveys," Journal of Marketing Research 14(3), 396-402. DOI: $10.2307 / 3150783$

Bejune, J. (2001). Wood Use Trends in the Pallet and Container Industry, Doctoral Dissertation, Virginia Polytechnics Institute and State University, Blacksburg, VA.

Bejune, J., Bush, R., Cumbo, D., Araman, P., Hansen, B. (2002). "Recycling behind most growth in pallet production," Pallet Enterprise 22(9), 26-37. (http://www.palletenterprise.com/articledatabase/view.asp?articleID=768), Accessed 19 Oct 2017.

Bond, J. (2018). "Pallet usage report: Users want more service \& support," Modern Materials Handling, (https://www.mmh.com/article/the_pallet_report_users_want_more_service_s upport), Accessed 7 September 2018.

Bumgardner, M. (2016). "Current state of the hardwood industry," SAFCEC Newsletter, (https://www.woodproducts.sbio.vt.edu/futurehardwoods/docs/Future_Status_ Bumgardner.pdf), Accessed 26 Jun 2019.

Bureau of Economic Analysis (2018). "Industry Data," (https://bea.gov/iTable/iTable.cfm?reqid=51\&step=51\&isuri=1\&5114=a\&510 2=1), Accessed 18 May 2018.

Bush, R. J., and Araman, P.A. (1998). "Changes and trends in the pallet industry: the use of new wood materials," Hardwood Market Report 76(9), 11-13.

Bush, R., and Araman, P.A. (2008). Updated Pallet and Container Industry Production and Recycling Research (Internal White Paper), Virginia Polytechnic Institute and State University, Blacksburg, VA.

Bush, R., and Araman, P.A. (2014). Trends in the Use of Wood Products for Distribution Packaging, (Cooperative Agreement No. 11-CA11330142-13), USDA Forest Service, Southern Research Station, Blacksburg, Virginia, USA. Blacksburg.

Christoforo, J. C. (1993). Wood Based Material Use in the United States Pallet and Container Industry, Master Thesis, Virginia Polytechnic Institute and State University, Blacksburg, VA.

Freedonia Group, Inc. (2017). "World Pallets”. https://www.freedoniagroup.com/industry-study/world-pallets-3126.htm, Accessed November 28, 2018. 
Haack, R. A., Britton, K. O., Brockerhoff, E. G., Cavey, J. F., Garrett, L. J., Kimberley, M., Lowenstein, F., Nuding, A., Olson, L. J., Turner, J., and Vasilaky, K. N. (2014). "Effectiveness of the international phytosanitary standard ISPM No. 15 on reducing wood borer infestation rates in wood packaging material entering the United States," PLOS One 9(5), 1-15. DOI: https://doi.org/10.1371/journal.pone.0096611

Institutional Review Board (2010). Human Subjects Protection Tutorial, IRB, Blacksburg, VA.

(http://www.irb.vt.edu/documents/downloadable_tutorial.pdf), Accessed 5 May 2018.

Joyce, L., Aber, J., McNulty, S., Dale, V., Handsen, A., Irland, L., Neilson, R., and Skog, K. (2001). "Current distribution of forests in the United States forest land coverage over the past 400 years," in Potential Consequences of Climate Variability and Change for the Forests of the United States, Cambridge University Press, Cambridge, England, pp. 609-612, (https://www.fs.fed.us/pnw/mdr/mapss/publications/pdf/17color.pdf), Accessed 22 Feb 2018.

Laerd Statistics. (2018). "Spearman's Rank-Order Correlation," Laerd Statistics, (https://statistics.laerd.com/statistical-guides/spearmans-rank-ordercorrelation-statistical-guide.php), Accessed 12 May 2018.

LeBlanc, R. (2011). "A history of pallets during World War 2: a call to action," Packaging Revolution, (https://packagingrevolution.net/a-history-of-palletsduring-world-war-2-a-call-to-action/), Accessed 8 Feb 2018.

Madison's Lumber Reporter (2018). "North America full-year 2016 lumber production: WWPA," Lumber Track, (https://madisonsreport.com/2017/03/16/north-america-full-year-16-lumberproduction-wwpa/), Accessed 25 Feb 2018.

Park, J., Horvath, L., and Bush, R. J. (2016). "Process methods and levels of automation of wood pallet repair in the United States," BioResources 11(3), 6822-6835. DOI: 10.15376

Raymond, S. (2007). "History of the hand pallet truck, " Raymond Handling, (https://raymondhandling.com/history-of-the-hand-pallet-truck/), Accessed 8 Feb 2018.

Reddy, V. S., Bush, R. J., Bumgardner, M., Chamberlain, J. L., and Araman, P. A. (1995). Wood Use in the U.S. Pallet and Container Industry: 1995 (Executive Summary Only), Virginia Tech, Blacksburg, VA, (https://www.srs.fs.usda.gov/pubs/ja/ja_reddy002.pdf), Accessed 7 Sept 2017.

Sanchez, L., White, M. S., Hagedorn, A. J., and Quesada Pineda, H. (2011). Identifying Success Factors in The Wood Pallet Supply Chain, Master's Thesis, Virginia Polytechnic Institute and State University, Blacksburg, VA, USA.

Shiner, Z., Horvath, L., and Araman, P.A. (2018). An Investigation of Wood Pallets Landfilled and Recovered at US Municipal Solid Waste (MSW)

Facilities, Master's Thesis, Virginia Polytechnic Institute and State University, Blacksburg, VA, USA.

Sustainable Forest Initiative (2019) "2018 SFI progress report." Sustainable Forestry Initiative, http://www.sfiprogram.org/files/pdf/2018-sfi-progressreport-summary/, Accessed 28, November, 2018. 
Tranpak (2018). "What are the standard pallet size dimensions?" Tranpack, (https://www.tranpak.com/tools/faq/standard-pallet-size-dimensions), Accessed 23 April 2018.

U.S. Census Bureau (2018). “American factfinder,” DOI: 10.5860/CHOICE.431925,_Accessed 28, November, 2018.

White, M. S., and McLeod, J. A. (1989). "Properties of shredded wood pallets," Forest Products Journal 39(6), 50-54.

World Bank (2018). "GDP (Current US\$)," (https://data.worldbank.org/indicator/NY.GDP.MKTP.CD?locations=US), Accessed 5 Dec 2017.

Article submitted: August 13, 2019; Peer review completed: December 21, 2019; Revised version received and accepted: January 10, 2020; Published: March 6, 2020.

DOI: 10.15376/biores.15.2.2818-2838 


\section{APPENDIX}

\section{Data Treatment}

General

- If responses to questions that asked for percentages did not add up to $100 \%$, they were excluded from the analysis.

- Responses to Question 5 were divided by responses to Question 7 to get board feet per pallet. The results were assessed using the assumed "reasonable" estimate of 0.5 to 30 board feet per pallet. If a response was off by a factor of 1,000 from what was assumed reasonable, it was assumed that the respondent had given their answer in board feet even though the question specifically asked for their answer in thousand board feet. In these cases, the respondents' board feet estimate was divided by 1,000 .

- The raw data can be found at http://ezid.cdlib.org/id/doi:10.7294/W43N21KM

Total Pallet Production

Questions used: $3 \& 5$

- Step 1: For each response, check to see if a value was given for number of pallets produced and employees. Remove all responses that did not provide both.

- Step 2: Sum the employee numbers and compare to the U.S. Census Bureau's industrywide employee numbers to determine the scale up factor.

- Scale up factor $=$ (U.S. Census Bureau employee numbers) / (employees accounted for in the reported pallet production).

- Step 3: Sum pallet production numbers.

- Step 4: Multiply the sum calculated in Step 3 by the scale up factor determined in Step 2 to acquire the national estimate.

Lumber Consumed

Questions used: $3 \& 7$

Step 1: On each questionnaire check to see if a value was given for employee numbers and for Question 7. Remove questionnaires that did not have both.

Step 2: Sum the employee numbers and compare to the U.S. Census Bureau's industrywide employee numbers to determine the scale up factor.

Scale up factor $=($ U.S. Census Bureau employee numbers $) /($ employees accounted for in the reported pallet production)

Step 3: Sum together lumber numbers and multiply the total by 1,000 to convert MBF to BF.

Step 4: Multiply scale up factor by the sum calculated in Step 3 to acquire national estimate.

Average Reported Sales Growth

Question Used: 4 
Step 1: Average all reported growths (including negatives) to get the estimated mean sales growth.

Proportions of Wood Species Consumed to Produce New Pallets

Questions used: 7, 8, \& 9

Step 1: On each questionnaire, check to ensure that all three questions were answered. Remove responses that did not answer all three questions.

Step 2: For each of the remaining questionnaires, sum the board feet used for new pallets as reported in Question 7.

Step 3: Multiply this summed board feet with the percentages reported in Question 8. This will reveal the volume of wood in each category: hardwood from the U.S., softwood from the U.S., and wood imported from outside the U.S.

Step 4: For each response, multiply the volumes calculated in step 3 by the percentage pertaining to them from Question 9. Multiply the "hardwood from the U.S." volume by the percentage of high, medium, or low density hardwood. Multiply the "softwood from the U.S." volume by the percentage for SPF, southern pine, Douglas-fir, or other North American softwoods. Multiply the volume of "wood imported into the U.S." by the percentages for the countries listed in Question 9.

Step 5: Sum the response for each species to calculate total reported volumes for each species.

Step 6: Divide the volume for each species by the summed total volume of all species to get the proportion that each species is of the total. Multiply by $100 \%$ to convert to a percentage of total wood consumed to produce new pallets.

Proportion of Pallet Sizes for New Pallets

Questions used: 5 \& 11

Step 1: On each questionnaire, check to ensure that both questions were answered. Remove responses that did not answer both questions.

Step 2: For each response, multiply the reported new pallets from Question 5 with the percentages for each size (from Question 11) to calculate each respondent's reported number of pallets of each size

Step 3: Sum the pallet amounts for each size.

Step 4: Divide the total number of pallets of each size by the sum of all sizes to get the proportion of total new pallets by size. Multiply by $100 \%$ to convert to a percentage of new wood pallets.

Proportion of Pallet Sizes for Recovered Pallets

Questions used: $13 \& 14$

Step 1: On each questionnaire, check to ensure that both questions were answered. Remove responses that did not answer both questions.

Step 2: For each response, multiply the reported number of recovered pallets from Question 13 with the percentage for each size of pallet as 
reported in Question 14 to calculate the reported number of pallets for each size.

Step 3: Sum the total pallets per each size.

Step 4: Divide the total pallets for each size by the sum of all sizes to get the proportion of total recovered pallets by size. Multiply by $100 \%$ to convert to a percentage of recovered wood pallets.

Proportion of Wood Consumed that was Imported from Outside the U.S.

Questions used: $7 \& 8$

Step 1: On each questionnaire, check to ensure that both questions were answered. Remove responses that did not answer both questions.

Step 2: For each remaining response, sum the amount of board feet reported in Question 7 for new pallets.

Step 3: Multiply the summed amount of board feet for each response with that responses percentages reported in Question 8. This will reveal how much volume of wood is in each category: hardwood from the U.S., softwood from the U.S., and wood imported from outside the U.S.

Step 4: Sum the wood imported from outside the U.S. to get the total reported wood.

Step 5: Divide the total reported wood imported from outside the U.S. by the summed total wood from Question 8. Multiply by $100 \%$ to convert to a percentage of new wood consumed to produce new pallets.

Proportion of New Wood Pallets that were Block or Stringer Pallets or Skids

Questions used: 5, 12

Step 1: For each response, check if both questions were answered. Remove responses that did not answer both questions.

Step 2: For each response, multiply the new pallets recorded in Question 5 by the percentages for block, stringer, and skid pallets from Question 12.

Step 3: Sum up the pallet amounts for each category of Question 12 to get the total reported value for each category.

Step 4: Divide the totals of each category (block, stringer, or skid) by the sum of all categories from Question 12. Multiply each result by $100 \%$ to get the proportion of each category for new pallets.

Proportion of Recovered Wood Pallets that were Block or Stringer Pallets or Skids

Questions used: 5, 15

Step 1: For each response, check if both questions were answered. Remove responses that did not answer both questions.

Step 2: For each response, multiply the recovered pallets recorded in Question 5 by the percentages for block, stringer, and skid pallets from Question 15.

Step 3: Sum up the pallet amounts for each category of Question 12 to get the total reported value for each category.

Step 4: Divide the totals of each category (block, stringer, or skid) by the sum of all categories from Question 12. Multiply each result by $100 \%$ to 
get the proportion of each category for recovered pallets.

Proportions of Uses for Wood Cores

Questions used: 13, 16

Step 1: For each response, check if both questions were answered. Remove responses that did not answer both questions

Step 2: For each remaining response, multiply the reported amount of cores received from Question 13 with the percentages reported in Question 16.

Step 3: Sum up the amounts of pallets that went into each use, as given in Step 2.

Step 4: Divide the total pallets used for each use by the total number of received cores. Multiply these results by $100 \%$ to get the total reported percentage from each category.

Step 5: The percent of pallets sold without repair and the percent of pallets repaired were added together and the total amount of repaired pallets from Question 5 was divided with this percent. The resulting number represented the total amount of cores received instead of the response received in Q13.

Step 6: The new number for the received cores were multiplied with the percentages from step 4 to calculate the total number of pallets in each category.

Wood Waste Tonnage and Proportions

Questions used: 17

Step 1: Sum all responses for the total tonnage of wood waste produced.

Step 2: Sum wood waste tonnage for each byproduct.

Step 3: Divide wood waste tonnage for each byproduct by the total tonnage of wood waste. Multiply each of these results by $100 \%$ to acquire the percentage of wood waste that went into making each byproduct. 